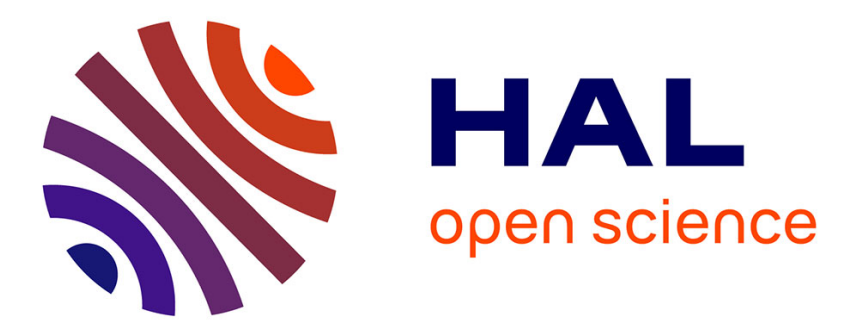

\title{
Development of an in-house cutting forces simulation for fir tree broaching process
}

Sébastien Mandrile, Gilles Cazenave-Larroche, Cyril Vernault, Gilles Dessein, Jean Denape, Jean-Yves Paris

\section{- To cite this version:}

Sébastien Mandrile, Gilles Cazenave-Larroche, Cyril Vernault, Gilles Dessein, Jean Denape, et al.. Development of an in-house cutting forces simulation for fir tree broaching process. International Journal of Machining and Machinability of Materials, 2014, vol. 15 ( $\left.\mathrm{n}^{\circ} 1 / 2\right)$, pp. 18-35. 10.1504/IJMMM.2014.059185 . hal-01139267

\section{HAL Id: hal-01139267 \\ https://hal.science/hal-01139267}

Submitted on 3 Apr 2015

HAL is a multi-disciplinary open access archive for the deposit and dissemination of scientific research documents, whether they are published or not. The documents may come from teaching and research institutions in France or abroad, or from public or private research centers.
L'archive ouverte pluridisciplinaire HAL, est destinée au dépôt et à la diffusion de documents scientifiques de niveau recherche, publiés ou non, émanant des établissements d'enseignement et de recherche français ou étrangers, des laboratoires publics ou privés. 


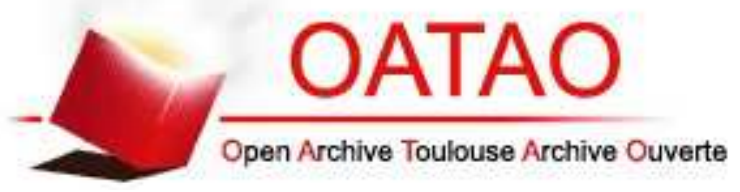

\section{Open Archive Toulouse Archive Ouverte (OATAO)}

OATAO is an open access repository that collects the work of Toulouse researchers and makes it freely available over the web where possible.

This is an author-deposited version published in: http://oatao.univ-toulouse.fr/ Eprints ID: 11214

To link to this article : DOI:10.1504/IJMMM.2014.059185

http://dx.doi.org/10.1504/IJMMM.2014.059185

\section{To cite this version:}

Mandrile, Sébastien and Dessein, Gilles and Denape, Jean and Larroche, Gilles Cazenave and Vernault, Cyril and Paris, Jean Yves Development of an in-house cutting forces simulation for fir tree broaching process. (2014) International Journal of Machining and Machinability of Materials, vol. 15 (n $\left.{ }^{\circ} 1 / 2\right)$. pp. 18-35. ISSN 1748-5711

Any correspondence concerning this service should be sent to the repository administrator: staff-oatao@ listes-diff.inp-toulouse.fr 


\title{
Development of an in-house cutting forces simulation for fir tree broaching process
}

\author{
Sébastien Mandrile*, \\ Gilles Cazenave-Larroche and Cyril Vernault \\ TURBOMECA, \\ 64511 Bordes, France \\ E-mail: Sebastien.Mandrile@turbomeca.fr \\ E-mail: Gilles.Cazenave-larroche@turbomeca.fr \\ E-mail: Cyril.Vernault@turbomeca.fr \\ *Corresponding author

\section{Gilles Dessein, Jean Denape and Jean-Yves Paris} \\ ENIT-INPT, \\ Laboratoire de génie de production, \\ Université de Toulouse, \\ 65000 Tarbes, France \\ E-mail: Gilles.Dessein@enit.fr \\ E-mail: Jean.Denape@enit.fr \\ E-mail: Jean-Yves.Paris@enit.fr
}

\begin{abstract}
This article proposes a simulation of cutting forces in broaching of fir tree slots. Every step needed to build an in-house fir tree broaching simulation is presented. This simulation is based on the discretisation of each tooth of the broach, computation of elementary cutting forces of each discretised section, and finally the summation of each elementary cutting force into a global axes system. This work also presents orthogonal cutting experiments to implement realistic specific cutting forces into the model. The simulation obtained is compared with the real force signals of a fir tree broach to evaluate the quality of the simulation. At the end, the application to industrial context is developed.
\end{abstract}

Keywords: broaching; specific cutting forces; cutting forces simulation; fir tree broach; broach design; fir tree slot.

Reference to this paper should be made as follows: Mandrile, S., Cazenave-Larroche, G., Vernault, C., Dessein, G., Denape, J. and Paris, J-Y. (2014) 'Development of an in-house cutting forces simulation for fir tree broaching process', Int. J. Machining and Machinability of Materials, Vol. 15, Nos. $1 / 2$, pp.18-35.

Biographical notes: Sébastien Mandrile obtained two Master degrees in Engineering and Material Science in 2010 from the Arts et Métiesr Paristech, France. He is currently a $\mathrm{PhD}$ candidate at Laboratoire Génie de Production (EA1905) (LGP) from the 'Ecole nationale d'ingénieur de Tarbes' (ENIT), France. His $\mathrm{PhD}$ thesis is a partnership between Laboratoire Génie de Production (LGP) and Turbomeca Safran Group Company. His domain of 
expertise is based on the modelisation of cutting forces and on the process monitoring in machining.

Gilles Cazenave-Larroche obtained his Master degree in Engineering from the 'Ecole nationale supérieure d'arts et métiers' - France. He has been gaining an experience in aerospace industry for 25 years. His current position is the Head of the Engineering Service in the Rotating Parts Department of Turbomeca Safran Group Company. His domain of expertise is based on machining of aeronautic parts.

Cyril Vernault obtained his $\mathrm{PhD}$ grade in Material Science from the University of Poitiers - France, in 1998. He has been gaining an experience in aerospace industry for 14 years. His current position is Machining and Heat Treatment Group Leader in the Engineering Department of Turbomeca Safran Group Company. His domain of expertise is based on heat treatment and machining of aeronautic parts.

Gilles Dessein is a Professor at Ecole Nationale d'Ingénieurs de Tarbes, University of Toulouse, France. He is a member of Laboratoire Génie de Production (EA1905) and manages machining research activities in the laboratory. He received his $\mathrm{PhD}$ degree from the University of Toulouse (1997) and an accreditation to supervise research (HDR) from the Institut National Polytechnique de Toulouse (2008). His expertise domain concerns high performance machining, and he has worked on dynamics in milling, hard materials machining, surface integrity, and behaviour of machine tools in the context of many European projects. His main expertise is in the analysis, monitoring, modelling, and control of machining processes.

Jean Denape is a Professor at the National Engineering School of Tarbes (ENIT), University of Toulouse, France. He is a member of the Production Engineering Laboratory (LGP, EA1905) and manages the Interfacial and Functional Materials research team in the laboratory. He received his $\mathrm{PhD}$ degree from the Mining School of Paris (1986) and an accreditation to supervise research (DSc) from the National Polytechnic Institute of Toulouse (1993). His domain of expertise concerns the durability of rubbing hard materials (structural ceramics and hard metallic alloys) under dry conditions or limit lubrication. He has been at the origin of the tribology activity at the LGP and developed it for 25 years. He developed more than ten tribometers for better understandings of wear mechanisms, dynamics of interfacial elements trapped in the contact (third body approach) and heat flow generated by friction through several national projects and international programmes.

Jean-Yves Paris is an Assistant-Professor at the National Engineering School of Tarbes (ENIT), University of Toulouse, France. He is a member of the Production Engineering Laboratory (LGP, EA1905) and belongs to the Interfacial and Functional Materials research team. He followed academic studies in material science and received his $\mathrm{PhD}$ degree from the University of Toulouse (1994). For 17 years, he has worked on tribology studies and performs topographic characterisations and physicochemical analyses on different materials (zirconia, alumina, titanium and nickel-base alloys, hard coatings, but also polymers and composites) to model matter transfers under different sliding conditions (pressure, speed, temperature, and atmosphere) for various dynamic configurations (rotating, reciprocating and fretting). His domain of expertise is based on local mechanical and physicochemical properties in relation to microstructure and also studies of surface damages after machining through several national projects and international programmes. 


\begin{abstract}
This paper is a revised and expanded version of a paper entitled 'Identification and modelisation of cutting phenomena in broaching to understand tool wear' presented at 7th Conference on High Speed Machining (MUGV 2012), SaintEtienne, France, October 2012.
\end{abstract}

\title{
1 Introduction
}

A fir tree slot is a junction between the disk and a blade in an aero-engine turbine. This assembly between the blade and the disk is an area of high thermal and mechanical loading. Broaching is used to machine the fir tree slot in the turbine disk. Turbine disks are usually in nickel-base alloys, called super-alloys. Nowadays, due to cycle time and machining quality, broaching is known to be the best process to machine fir tree slots in aero turbine disk. Broaching process guarantees a high quality level of surface integrity and slot geometry. However, some drawbacks can be observed: some expensive parts may be damaged as a consequence of tool wear and cutting disturbances, because of very tight geometrical tolerances of the fir tree and the very intrinsic difficulty to machine the nickel-base alloys.

Moreover, for a given broach shape, there is only one machining parameter which can be changed: the cutting speed. The others are given by the tool shape.

Fir tree broach does not produce constant force signals. The interpretation of these non-constant force signals is not possible to get directly because several teeth machine at the same time. For a better understanding of the broaching process, cut sections and specific cutting forces on each tooth must be taken into account with regard to the force signals. This article proposes a methodology to simulate cutting forces in broaching on the basis of the discretization of each tooth and computation of several cutting parameters. This simulation was done with MATLAB ${ }^{\circledR}$ software. Afterwards, the simulation was compared to a real fir tree broaching to evaluate its quality.

\section{Bibliography}

Simulation of cutting forces has become very common in the field of machining and in its literature. Nowadays, it is known as a great help to understand the cutting process.

More than 25 years ago, Amarego and Withfield (1985) proposed a unified theory to simulate cutting forces in milling, turning and drilling based on a simple series of oblique cutting tests. Cutting force models in the three directions were estimated by regression depending on the oblique cutting tests. Simulation was operated by the discretization of the tool cutting edge and by application of the cutting forces model on each discretized section. Ten years after, Budak et al. (1996) proposed a simplified methodology of this prior model. They still used the cutting edge discretization with a three component cutting force model. The innovation came from the cutting force model which was not estimated by oblique cutting tests but by orthogonal cutting tests. This solution is an improvement due to the simplification of the characterisation of the model. Stephenson and Bandyopadhyay (1997) presented another possible solution to simulate cutting forces. Their methodology was based on the computation of an equivalent cut section, in 
opposition to the discretization of the cutting edge. This is another possible solution to simulate cutting forces.

Unlike the other cutting processes (turning or milling) in which it is possible to find either commercial solutions of cutting force simulation or articles about cutting force simulation, there is still a lack of study about broaching and its simulation. Currently broaches are designed with norms, and only a few number of studies deals about cutting forces simulation in broaching.

Bellais (1997) described the norm used to develop a broach. He indicates how to choose the parameters of a broach, but it does not establish neither a methodology to simulate the cutting forces nor an evaluation of the cutting parameters in each discretized section of the broach. To determine broach parameters, Terry et al. (1992) did not proceed by simulation of cutting forces, but by a series of equations like Taylor's tool life equation and maximum stress admitted by the broach. This solution, computer-assisted, proposes broach parameters not far away from the norms because the equations implemented in this software come from the norms themselves. This computation does not allow a simulation of the cutting forces. Ozturk and Budak (2003) and Kokturk and Budak (2004) proposed a simulation of the cutting forces in broaching with an in-house software. Those two articles are very interesting because they deal about the broaching of fir tree slots. This simulation is used to determine the part deflection and then they could determine the maximal admissible force to limit the part deflection. Other criteria, like maximum tooth stress, were also determined, and a multi-criteria optimisation algorithm chooses tools parameters. Most of these articles use cutting force simulation only as a step of calculation to solve a multi-criteria optimisation algorithm. As far as we know, Sutherland et al. (1997) is the only article which only deals about cutting forces in broaching, without multi-criteria optimisation algorithm... This article presents the simulation of cutting forces in helicoidal gear broach. Very recently Zhang and Chen (2012) proposed a simulation of the cutting forces in nickel-base alloys. This simulation was done by a two-dimension finite element method in orthogonal cutting with only one tooth. As a consequence, this simulation is not directly transposable to our case, which deals with simulation of cutting forces in broaching in order to understand cutting mechanisms in each section of the broach.

In conclusion, examples of cutting force simulation in classical machining operation (milling, turning, and drilling), as in broaching, demonstrate the interest of cutting force simulations to improve the understanding of the cutting process occurring in very complex machining operation. For classical machining process, commercial application of cutting force simulation are available as well as articles describing the methodology to manage a simulation. For broaching, it remains necessary to develop realistic in-house cutting force simulation software, to be as close as possible to the process.

\section{Cutting experiments and modelisation}

\subsection{Experimental set-up}

Simulation of the cutting force previously requires a series of experiments for two reasons:

- the implementation of the cutting force models 
- the verification of the simulated cutting forces.

Each test, performed to identify the cutting force models and to verify the simulation, was done using a $\mathrm{CNC}$ broaching device equipped with an electric ram [Figure 1(a)]. This machine allows a maximum pushing force of $10 \mathrm{kN}$ for a range of cutting speed from 0 to $20 \mathrm{~m} / \mathrm{min}$. Figure 1 (a) presents the experimental set-up with the broaching machine and the dynamometer. Figure 1(b) presents the three axes system on the fir tree slots to measure the cutting forces. This machine is also equipped with an integrated force sensor to measure the pushing force of the machine. Force in the $\vec{z}$ axis represents the pushing force of the broaching machine. Measurement of the cutting forces was done by a Kistler 9255A three axes dynamometer [Figure 1(a)]. This sensor was chosen for two reasons:

- Its loading capacity (40 kN in the axis $\vec{z}$ and $20 \mathrm{kN}$ in the $\vec{x}$ and $\vec{y}$ axes).

- The possibility to fix a platform on the top to clamp the workpiece and other sensors like accelerometers. The use of a platform for broaching has already been done by Axinte and Gindy (2003).

To limit noise on the measure, a low pass-filter was applied on the measured signals with a cut-off frequency of $50 \mathrm{~Hz}$.

Figure 1 Broaching machine and dynamometers experimental set-up (see online version for colours)

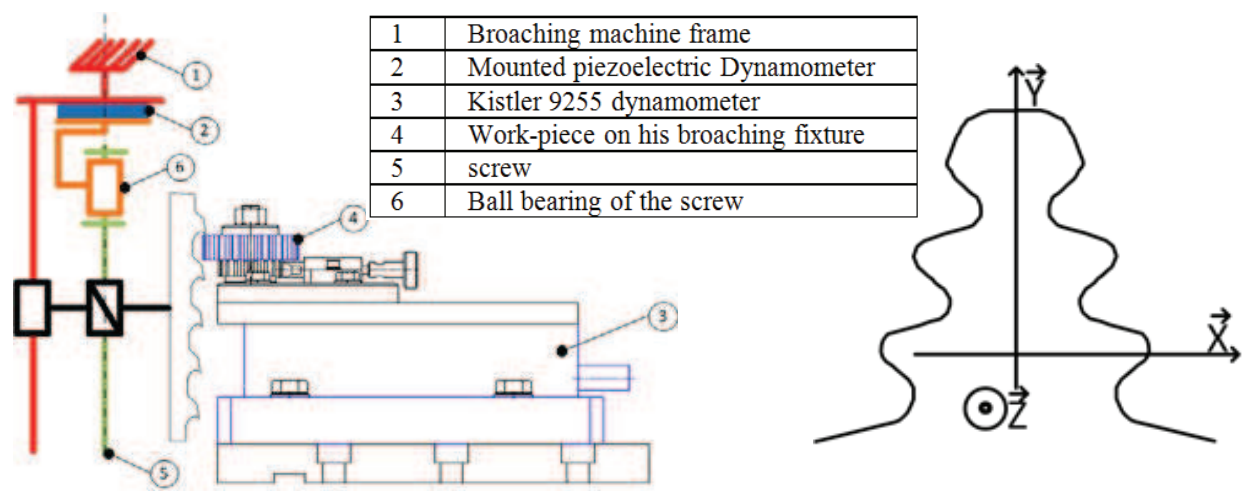

(a)

(b)

\subsection{Cutting force model}

\subsubsection{Experimental plan}

The goal of these experiments is to provide a cutting force model to implement the cutting force simulations. But, as explained before, every cutting test was performed on an industrial broaching machine used by the production. It means that the experimental design must be very short, to limit the non-production time of the broaching machine. The choice of orthogonal cutting test was done to reduce the number of tests. The cutting speed was chosen as a constant because, in broaching, during one machining, cutting speed is constant in every part of the tool. Due to the very complex shape of the fir tree 
slot [Figure 1(b)], feed per tooth and rake angle change along the cutting edge of each tooth. That is why the experimental design must include the rake angle and the feed per tooth with multiple levels. Rake angles used by the turbine disk manufacturers for nickel-base alloys are generally ranged from 8 to 18 degrees, and feed per tooth ranged from $0.02 \mathrm{~mm}$ in finishing to $0.08 \mathrm{~mm}$ in roughing. High speed steels tools are used. New tools were used for each trial. The influence of the tool wear is not taken into account in this work, but integration of wear can be a future development of the simulator. The cutting edge is sharp from the grinding and not prepared by a special radius or chamfer: its measure gives a radius around 4 to $7^{\circ} \mu \mathrm{m}$. According to the explanations given just above, the experimental design follows a full factorial experimental approach as shown in Table 1. Each condition was repeated three times.

Table 1 Parameters of the experimental design

\begin{tabular}{lcccc}
\hline Feed per tooth $(\mathrm{f})$ & 0.02 & 0.05 & 0.08 & $\mathrm{~mm} /$ tooth \\
Rake angle $(\gamma)$ & 8 & 13 & 18 & Degrees \\
\hline
\end{tabular}

\subsubsection{Orthogonal cutting test}

During this study, the machined material is a nickel-base alloy, Udimet ${ }^{\circledR} 720$, used to produce rotating parts in aero engines. The orthogonal cutting tests were carried out with one tooth orthogonal tools [Figure 2(a)]. Recorded outputs are the cutting force $\left(F_{t}\right)$, the thrust force $\left(F_{r}\right)$ and the chip thickness $(h)$. Figure 2(b) shows the workpiece and the broaching tool with the chip formation, recorded with a high speed camera. Those videos were used to explain the shape of the force signals illustrated in Figure 3.

Figure 2 Orthogonal cutting test configuration and a picture extracted from the high speed camera film (see online version for colours)

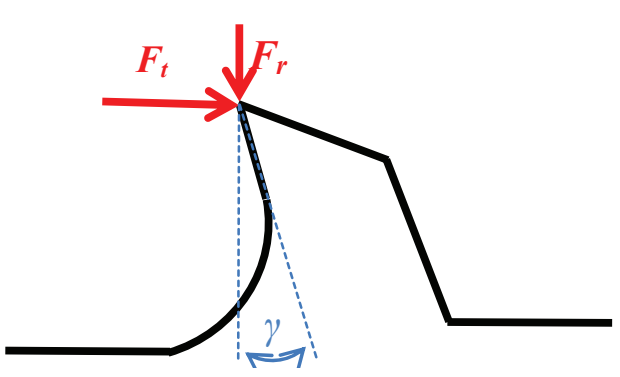

(a)

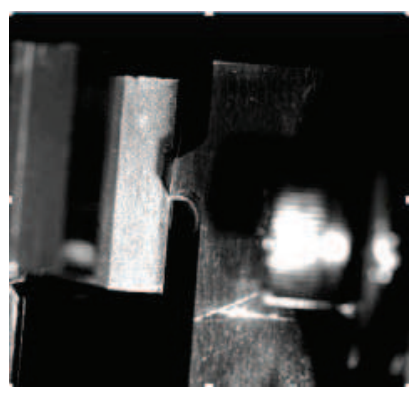

(b)

Figure 3(a) considers the evolution of the cutting force versus the time. Despite of the zero inclination angles due to the orthogonal configuration, forces do not reach a maximum directly but increase progressively. Explanations of the five events given in Figure 3(b) come from the observation of high speed movies [Figure 2(b)]. The high speed camera movies prove that the chip does not rub in the gullet before the event 4 on Figure 3. Unlike what was done in Mandrile et al. (2012), force pattern on Figure 3 is only due to a little deflection of the workpiece clamping during the tool entrance and not to the chip rubbing in the gullet or chip forming initiation. Observations using the high speed camera, correlated with force measurement reveal that the chip rubbing in the 
gullet has only a slight effect on cutting forces. As far as we know, no study proposes a model for chip forming initiation and the present authors have not modelised this phenomenon. The force average during the 'constant chip rubbing in the gullet', which corresponds to the event 5 on Figure 3(a), was chosen to implement the cutting models.

Figure 3 Shape of the forces signals (see online version for colours)

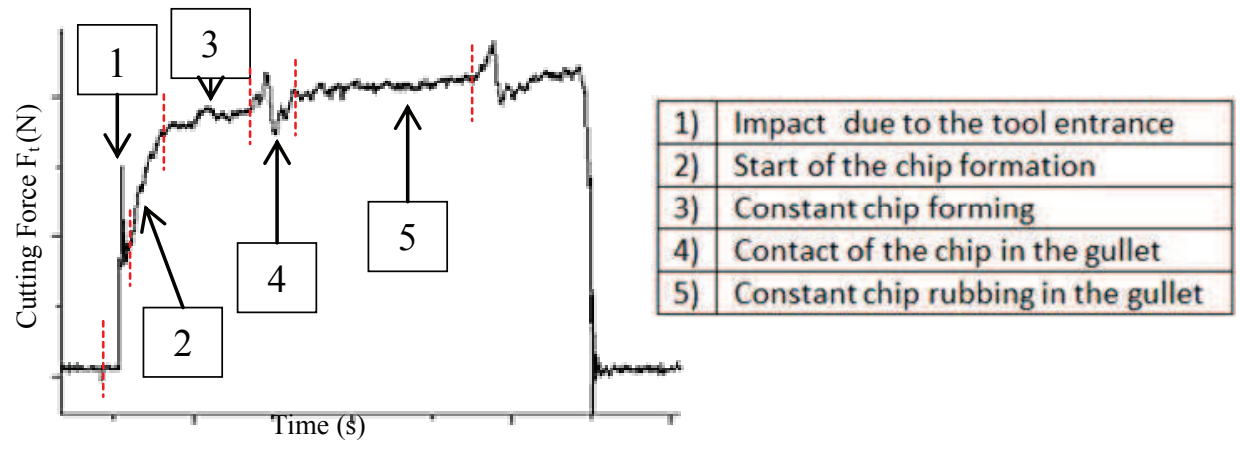

(a)

(b)

Results of the orthogonal cutting tests are presented with a normalised form in Figure 4. This normalisation is presented in equation (1), $K_{t}$ and $K_{r}$ values are in megapascals. Figure 4 shows that normalised cutting forces decrease with the increase of the feed per tooth $(f)$ and the rake angle $(\gamma)$. Another important thing is the large range of variation of the normalised cutting forces, $K_{t}$ fluctuate from $9,000 \mathrm{MPa}$ for $f=0.02 \mathrm{~mm}$ and $\gamma=8$ to $3,500 \mathrm{MPa}$ for $f=0.08 \mathrm{~mm}$ and $\gamma=18$. As expected, specific cutting forces calculated for this nickel-base alloy are very high (Figure 4 ). These values of $K_{t}$ and $K_{r}$ induce very high forces and high temperature during machining which involves very fast broach wear. During this study, broaches are made out of high speed steel tools. Both graphs, on Figure 4, justify the interest to understand and to control each cutting parameter of the broach, to improve productivity and quality of the machined parts.

$$
K_{t}=\frac{F_{t}}{(b \times f)} K_{r}=\frac{F_{r}}{(b \times f)}
$$

Figure 4 Evolution of normalised forces versus the rake angle and the feed per tooth (see online version for colours)
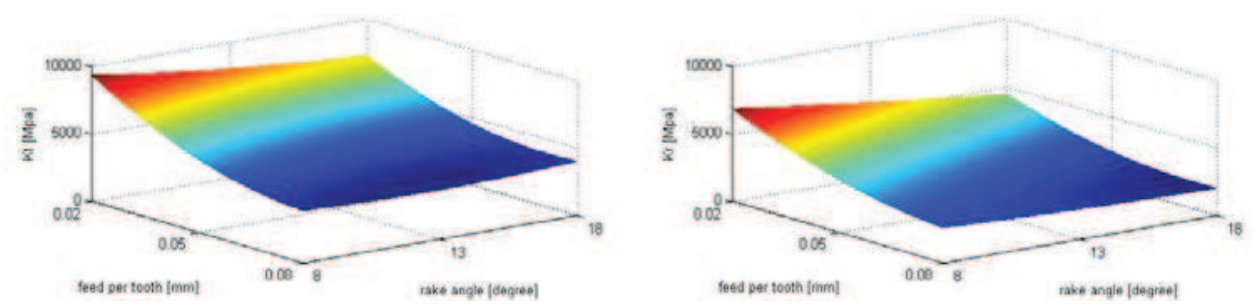


\subsubsection{Cutting models}

Cutting models results from an experimental work implemented in the cutting force simulation. Two types of cutting models were applied for this simulation (one for orthogonal cutting and the other for oblique cutting):

Model 1 orthogonal cutting (Albrecht, 1960)

Model 2 oblique cutting model (Budak et al., 1996).

The first model (orthogonal cutting) neglects the inclination angle $\left(\lambda_{s}\right)$ of the real fir tree broach (which is around 1.4 degrees). This approximation allows the use of a two-dimension model [as shown by equation (2)]. The forces $F_{t c}$ and $F_{r c}$ represent the cutting and the thrust forces due to the rake face. The forces $F_{t s}$ and $F_{r e}$ represent the forces due to the cutting edge. Forces $F_{t c}, F_{r c}, F_{t e}$ and $F_{r e}$ are given by equation (3).

$$
\begin{aligned}
& F_{t}=F_{t c}+F_{t e} \\
& \left.F_{r}=F_{r c}+F_{r e}\right\} \\
& F_{t c}=K_{t c} \times f \times b \quad F_{t e}=K_{t e} \times b \\
& \left.F_{r c}=K_{r c} \times f \times b \quad F_{r e}=K_{r e} \times b\right\}
\end{aligned}
$$

The parameter $b$ is the width of cut of each discretized teeth and $\mathrm{f}$ is the feed per tooth of each discretized tooth. For this very simple model, modelisation of the chip thickness is not necessary. Coefficients $K_{t c}, K_{t e}, K_{r c}$ and $K_{r e}$ are evaluated by a polynomial equation from orthogonal cutting tests. The equation (4) shows the polynomial form used to calculate coefficient $K_{t c}$. The coefficients $a_{t c}, b_{t c}, c_{t c}, d_{t c}, e_{t c}$ and $f_{t c}$ come from the regression. The polynomial form for the three other coefficients are similar.

$$
K_{t c}=a_{t c} \times f+b_{t c} \times \gamma+c_{t c} \times f^{2}+d_{t c} \times \gamma^{2} e_{t c} \times f \times \gamma+f_{t c}
$$

The second model (oblique cutting model), as the previous model, does not require approximation about the inclination angle $\left(\lambda_{s}\right)$ anymore. It means that it becomes necessary to add a third force. Equation (5) shows this third force included in the model.

$$
\left.\begin{array}{l}
F_{t}=K_{t c} \times f \times b+K_{t e} \times b \\
F_{r}=K_{r c} \times f \times b+K_{t e} \times b \\
F_{a}=K_{a c} \times f \times b+K_{a e} \times b
\end{array}\right\}
$$

This three-dimension forces model requires to compute the coefficients $K_{t c}, K_{r c}, K_{a c}$ the modelisation of the shear angle $\left(\phi_{n}\right)$ by equation (6), the shear stress in the primary $\left(\tau_{s}\right)$ by equation (7) and the friction coefficient on the rake face $\left(\beta_{n}\right)$ by equation (8). Parameters $\phi_{n}, \tau_{s}$ and $\beta_{n}$ are determined by polynomial equations as a function of feed per tooth $(f)$ and rake angle $(\gamma)$, as equation (4). Then, it is possible to compute $k_{t c}, k_{r c}$ and $k_{a c}$ by the system of equation (9).

$$
\phi_{n}=\frac{\frac{h}{f} \times \cos (\gamma)}{1-\left[\frac{h}{f} \times \sin (\gamma)\right]}
$$




$$
\left.\begin{array}{l}
\tau_{s}=\frac{\left\lfloor F_{t c} \times \cos \phi_{n}-F_{r c} \times \sin \left(\phi_{n}\right)\right\rfloor \times \sin (\gamma)}{b \times f} \\
\tan \left(\beta_{n}\right)=\frac{F_{r c}+F_{t c} \times \tan (\gamma)}{F_{t c}-F_{r c} \times \tan (\gamma)} \\
k_{t c}=\frac{\tau_{s}}{\sin \left(\phi_{n}\right)} \times \frac{\cos \left(\beta_{n}-\gamma n\right)+\tan ^{2}\left(\lambda_{s}\right) \times \sin (\beta n)}{c} \\
k_{r c}=\frac{\tau_{s}}{\sin \left(\phi_{n}\right) \times \cos \left(\lambda_{s}\right)} \times \frac{\sin \left(\beta_{n}-\gamma_{n}\right)}{c} \\
k_{a c}=\frac{\tau_{s}}{\sin \left(\phi_{n}\right)} \times \frac{\left[\cos \left(\beta_{n}-\gamma_{n}\right)-\sin \left(\beta_{n}\right)\right] \times \tan \left(\lambda_{s}\right)}{c} \\
c=\sqrt{\cos ^{2}\left(\phi_{n}+\beta_{n}-\gamma_{n}\right)+\tan ^{2}\left(\lambda_{s}\right) \times \sin ^{2}\left(\beta_{n}\right)}
\end{array}\right\}
$$

The coefficients $K_{t s}$ and $K_{r e}$ are also determined by polynomial regression from orthogonal cutting tests, like for the first model. The coefficient $K_{a s}$ is determined by equation (10) as already done by Amarego and Withfield (1985). Due to the very small value of $K_{a e}$, given by equation (10), most of the publications which use this model simplify this parameter $K_{a e}$ by zero like in Budak et al. (1996). With $\lambda_{s}=1.4^{\circ}$ the value of $K_{a e}$ is equal to: $K_{a e}=K_{r s} \times 0.023$, which is a very low value. Example of the low value of $F_{a}$ due to $K_{a c}$ and $K_{a e}$ is given in Section 6 of this article.

$$
K_{a e}=K_{r e} \times \sin \left(\lambda_{s}\right)
$$

\section{Simulation of the cutting forces in broaching}

\subsection{Geometrical description of the broach}

Prior to simulate cutting forces in broaching and to use the cutting force models, it is necessary to characterise the fir tree broach geometrically. Because the most difficult point is not to obtain the cutting coefficient, the real difficulty is the geometrical description of the broach, and then to know the cutting section taken by each tooth. The first step is the description of the roughing and the finishing of the fir tree slot. Figure 5 shows in red the shape of the fir tree slot and in blue the shape left by the roughing. These two shapes are mathematically characterised by three matrixes. Matrixes $X_{\text {fir } \text { rree }_{\text {slo }}{ }_{n-1}}$ and $X_{\text {roughing }_{n-1}}$ represent the $x$ coordinates of the slot (given by the industrial) versus the matrix $Y_{\text {slot discretization }_{n-1}}$ which represents the discretization of the slot along the $\vec{y}$ axis. Matrixes $X_{\text {fir tree slot }_{n-1}}$ and $X_{\text {roughing }_{n-1}}$ are $n$ lines and 1 colon matrixes. $n$ is equal to the high of the fir tree $(H)$ divided by the discretization on the fir tree $(d)$. Generally, the value of $\mathrm{d}$ is $0.01 \mathrm{~mm}$. 
Figure 5 Roughing and finishing shape of the fir-tree slot (see online version for colours)

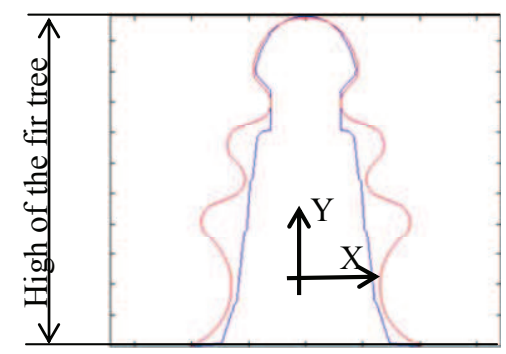

The second step is the automatic generation of the broach teeth (by an algorithm) depending on the position of the first tooth, the rise per tooth, the roughing and the finishing shape matrixes. Figure 6 shows all the teeth of the broach between the roughing and the finishing shapes. Each different line deals with a different tooth of the broach.

Figure 6 The broach teeth between the roughing and the finishing shapes (see online version for colours)

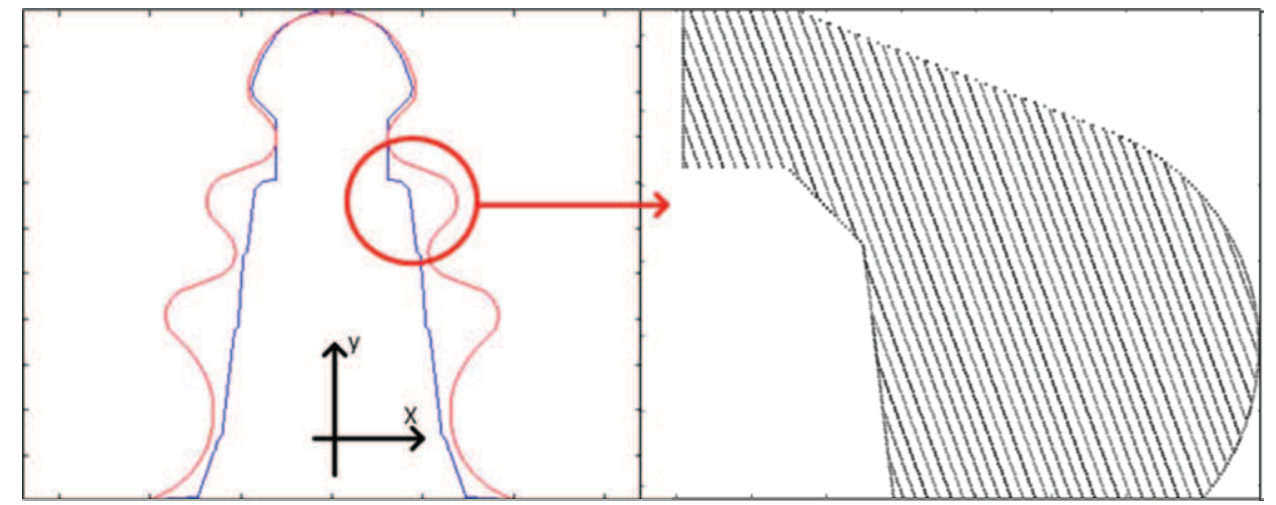

(a)

(b)

The position of the first tooth is given by the matrixes $X_{\text {broach first tooth } n^{*} 1}$ and $Y_{\text {slot discretization }_{n^{*} 1}}$. The matrix $X_{\text {broach first tooth }_{n^{*} 1}}$ is simply the $x$ coordinate of the first tooth, that is to say the coordinate of a line. The $y$ coordinates are still given by $Y_{\text {slot discretiztion }_{n^{*} 1}}$. The matrixes which characterise the teeth of the broach are $X_{\text {broach teeth }_{n^{*} m}}$ (with $n$ lines and $m$ colons equal to the number of teeth) for the $x$ coordinates and $Y_{\text {slot discretization }_{n^{*} 1}}$ for the $y$ coordinates. The result of matrix $X_{\text {broachteeth }_{n^{*} m}}$ is plotted in Figure 6(b). As explained above, each coloured line is a different tooth of the broach. The distance between two consecutive teeth is the feed per tooth. In this example, the feed per tooth is equal to $0.03 \mathrm{~mm}$. All the teeth (colons of the matrix $X_{\text {broach teeth } n_{n^{*} m}}$ ) are generated by the following algorithm [the result of this algorithm is given in Figure 6(b)]: 


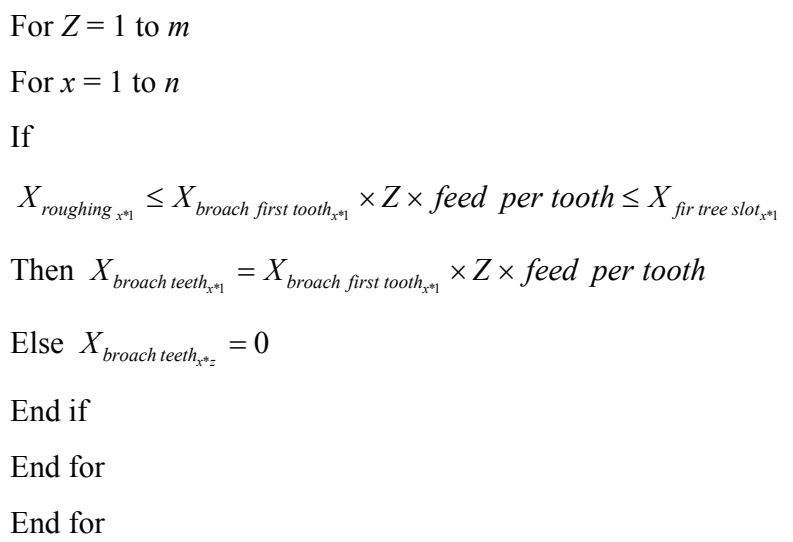

\subsection{Computation of the elementary cutting forces}

Computation of the elementary cutting forces is based only on the two matrixes

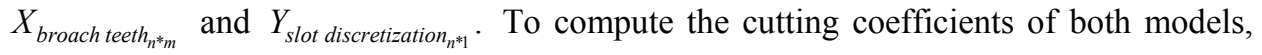
and after elementary cutting forces, some preliminary computations are needed. These preliminary computations are the computations of parameters which characterise the cutting coefficients. These parameters of each discretized sections are: the feed per tooth $(f)$, the width of cut $(b)$, the vectors $(\vec{t}, \vec{r}, \vec{a})$ which give the directions of the elementary forces $F_{t}, F_{r}, F_{a}$, the normal rake angle $\left(\gamma_{n}\right)$ and the inclination angle $\left(\lambda_{s}\right)$. After that, for model 1 , cutting coefficients are computed by equation (4) and elementary forces obtained by equations (2) and (3). For model two, cutting coefficients on the rake face are computed by equation 9 and elementary cutting forces by equation (5).

The first step is the computation of the radial $(\vec{r})$ and axial $(\vec{a})$ vectors of each discretized section of each tooth. Figure 7(a) shows the roughing and the finishing shape of the fir tree slot (like Figure 6). Figure 7(a) shows also one tooth with a discretized section and its radial and axial vectors. Figure 7(b) focuses on the discretized section shown in Figure 7(a). It presents the feed per tooth $(f)$ and wide of cut $(b)$ of each discretized section of each tooth. The feed per tooth $f$ of each discretized tooth is represented by the matrix $f_{\text {broacch }_{n^{*} m} m}$. The computation of $f_{\text {broach }_{n^{*} m}}$ is done by the equation (11). The tangential vector $(\vec{t})$ of each discretized section of each tooth is not represented here because it is directly parallel of the $\vec{z}$ axis. Vectors $\vec{t}, \vec{r}$ and $\vec{a}$ are used to direct $F_{t}, F_{r}, F_{a}$ from both cutting models.

$$
f_{\text {broach }_{y^{*} x}}=X_{\text {broach teeth }_{*_{x}}}-X_{\text {broach teeth }_{y^{*}(x-1)}}
$$


Figure 7 Axial and radial vector of each discretized section of a tooth (see online version for colours)

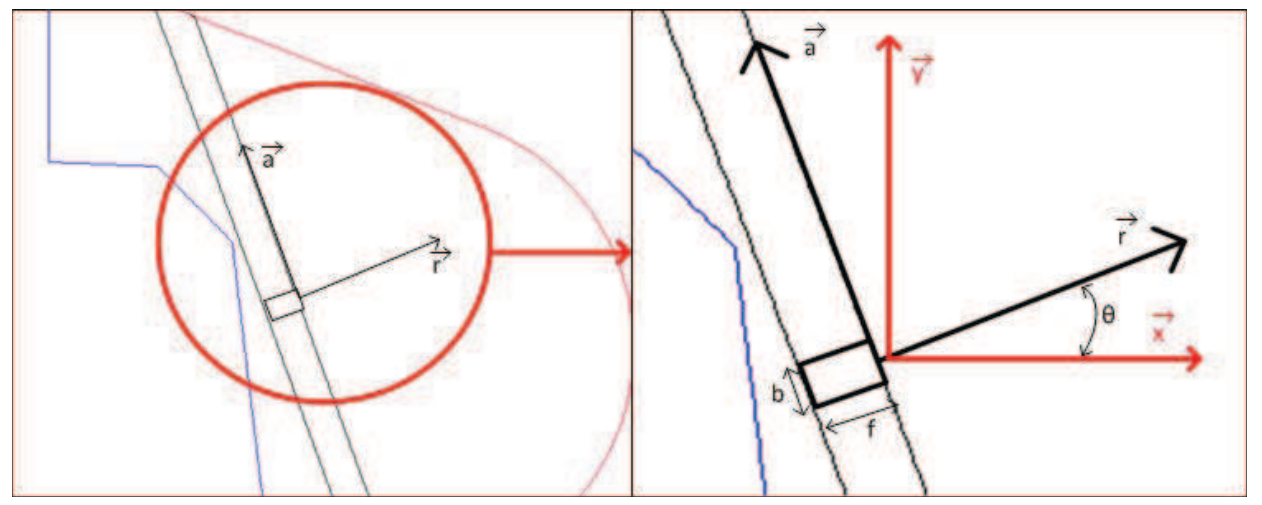

The second step is the computation of the rake angle and the inclination angle. To use both cutting forces models, the normal rake angle $\left(\gamma_{n}\right)$ and the inclination angle $\left(\lambda_{s}\right)$ have to be calculated. Equation (12) shows the three steps of computations needed to compute $\gamma_{n}$ and $\lambda_{s}$. The rake angle $\gamma$ is the angle given during the grinding of the broach, the angle $\gamma_{o}$ is the orthogonal rake angle. The angle $\theta$ is shown in Figure 6 is equivalent to the orientation angle $\left(K_{r}\right)$.

After computation of $f, b, \vec{t}, \vec{r}, \vec{a}, \gamma_{n}$ and $\lambda_{s}$ it is now possible to calculate (using parameters of both cutting models) the elementary cutting forces $F_{t}, F_{r}, F_{a}$ of each section of each tooth. Computation of the forces along the $\vec{x}, \vec{y}, \vec{z}$ axes [Figure 7(b)] is carried out by equation (13). The outputs of this paragraph are three matrixes, $F_{x_{n^{*} m}}, F_{y_{n^{*} m}}$, $F_{z_{n^{*} m}}$ with $n$ lines et $m$ colons.

$$
\begin{aligned}
& \tan \left(\gamma_{o}\right)=\cos (\theta) \tan (\gamma) \\
& \tan \left(\lambda_{s}\right)=\sin (\theta) \tan (\gamma) \\
& \tan \left(\gamma_{n}\right)=\cos \left(\lambda_{s}\right) \tan \left(\gamma_{o}\right) \\
& F_{z} \cdot \vec{z}=F_{t} \cdot \vec{t} \\
& \left.F_{x} \cdot \vec{x}=F_{r} \cdot \cos (\theta) \cdot \vec{r}-F_{a} \cdot \sin (\theta) \cdot \vec{a}\right\} \\
& F_{y} \cdot \vec{y}=F_{r} \cdot \sin (\theta) \cdot \vec{r}+F_{a} \cdot \cos (\theta) \cdot \vec{a}
\end{aligned}
$$

\subsection{Summation of the elementary cutting forces in the global cutting forces}

Elementary forces $F_{x}, F_{y}$, and $F_{z}$ along the $\vec{x}, \vec{y}, \vec{z}$ axes are now associated to each discretized section of each tooth. But, because broaching is a non-constant cutting process due to the teeth entering/exiting, direct summation of each elementary force is not possible. Figure 8 illustrates the summation technic used to obtain global forces versus the broach displacement. Other parameters must be added to this algorithm: the pitch of the broach $(P)$, the workpiece thickness $(e p)$, the discretization of the broach 
displacement (disp), the length of the broach (le) and the inclination angle of the workpiece $\left(\alpha_{\text {workpiece }}\right)$.

The summation technic is the following: the broach displacement along the $\vec{z}$ axis is simulated by a loop. If the tooth is located between the lower and the upper limit, the elementary forces are summed in to 'Global Force of each Tooth matrixes'. These matrixes are called $G F T_{x_{r^{*} m}^{*}}, G F T_{y_{r^{*} m} m}, G F T_{z_{r^{*} m} m}$ with $r$ lines and $\mathrm{m}$ colons. $m$ is still the number of teeth in the broach and $r$ is equal to the equation (14). These matrixes give the forces during the broach displacement for each tooth, which means that most of the lines (broach position $r$ ) of each colon (tooth $m$ ) are filled with zeros. The 'Global Forces' along the broach displacement are obtained by summation of every colon of each line of $G F T_{x_{r^{*} m_{m}}}, G F T_{y_{r^{*} m}}, G F T_{z_{r^{*} m} m}$. Global forces matrixes along the broach displacement are

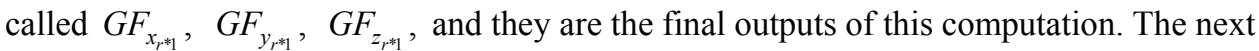
paragraphs will present the results of global forces matrices.

Figure 8 Broach displacement for the summation of the elementary forces

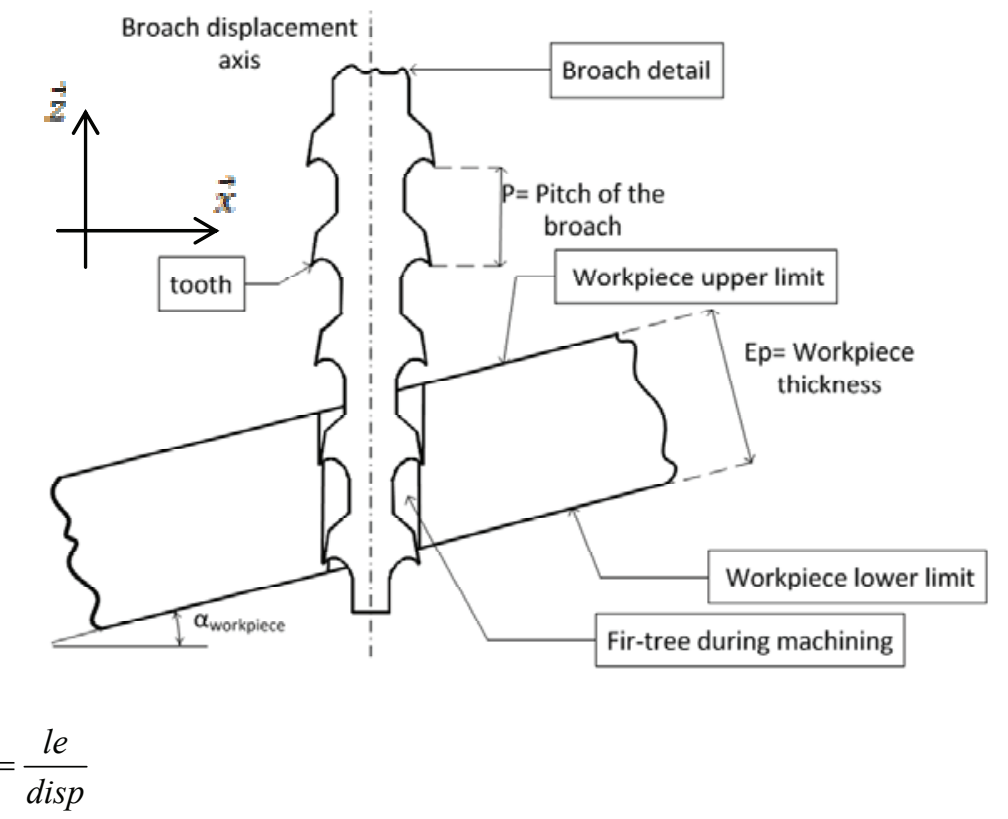

\section{Comparison between simulations and measured cutting forces}

Figure 9 shows the global cutting forces along the $\vec{x}, \vec{y}, \vec{z}$ axes for both models. Figure 9(a) shows the results of the first model and Figure 9(b) the results of the second model. Both models give very similar results. This observation can be explained by the very low inclination angle. For most of the discretized sections of each tooth $\lambda_{s}=1.4^{\circ}$, it means a very low value of $k_{a c}$. The maximum value of axial force $F_{a}$ was checked and was found around $14 \mathrm{~N}$, which is a very low value compared to more than $1,000 \mathrm{~N}$ for the radial force $F_{r}$. After projection on $\vec{x}$ and $\vec{y}$ axes, $F_{a}$ becomes negligible. Both models 
along the three axis present similar results with a maximum difference of $4 \%$, as presented in Figure 10.

Figure 9 Global forces versus the broach displacement in the $\vec{x}, \vec{y}, \vec{z}$ axes, (a) model 1 (b) model 2 (see online version for colours)

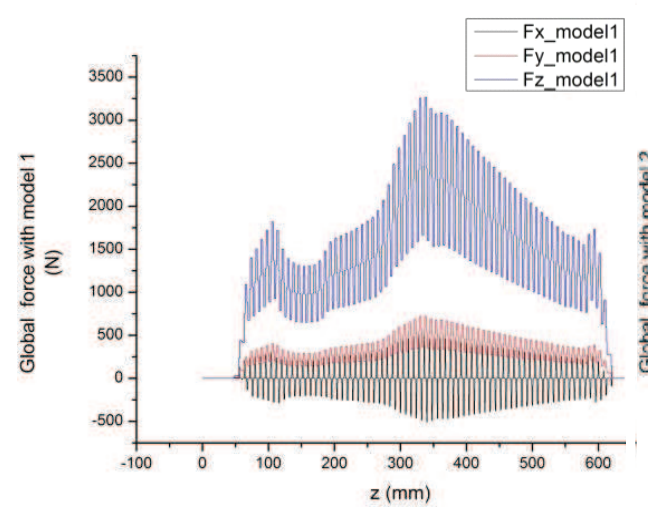

(a)

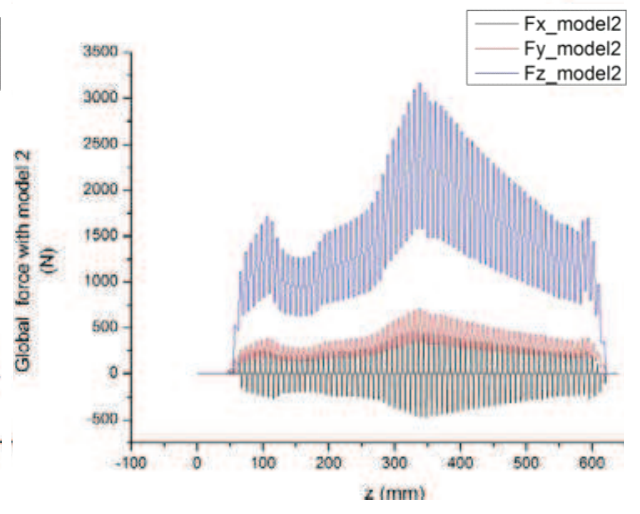

(b)

Figure 10 Percentage of differences between models one and two

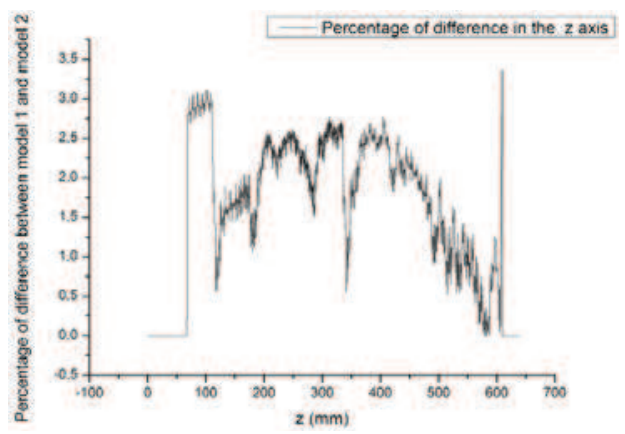

The next pictures present the comparison between the simulated forces from model 1 [Figure 11(a)] and the measured forces on a real fir tree broach [Figure 11(b)]. As it is possible to see, simulated forces in the $\vec{z}$ axis agree very well with the measured forces. Simulated forces in the $\vec{x}$ and $\vec{y}$ axes agree very well until the abscissa of $600 \mathrm{~mm}$. After this abscissa, cutting forces present the same proportions but with a deviation. Because of the symmetrical shape of the fir tree (Figure 1), the force on the $\vec{x}$ axis has to be centred on zeros as for simulation [Figure 11(a)]. This deviation can be explained by the roughing of the fir tree (Figure 5). By opposition to the finishing shape done with one tool, the roughing shape is done with nine consecutive tools. Each tool of the roughing has a position tolerance in the shape. This tolerance can change the shape of the roughing and then change the cutting sections taken by the teeth of the finishing tool. This modification of shape can induce a more important wear of the teeth which cuts this area, as already pointed in Mandrile et al. (2012). 
This hypothesis based on the deviation of $F_{x}$ has to be confirmed by metrology of the roughing and the finishing shapes. In the simulation, if the roughing or the finishing shapes are modified, to take into account the lack of alignment of certain tools of the broach, the simulation becomes a way to evaluate the broach manufacturing tolerance and then a possibility to improve the process in terms of conception and process monitoring. Except for the problem of force direction deviation, the maximum error of the simulation is $10 \%$, mainly due to the manufacturing precision of the broach and the accuracy of the cutting models. The broach used for Figure 11(b) presents only a fir tree machining strategy and not a dovetail machining strategy at the end of the tool.

Figure 11 Simulated and measured forces (see online version for colours)

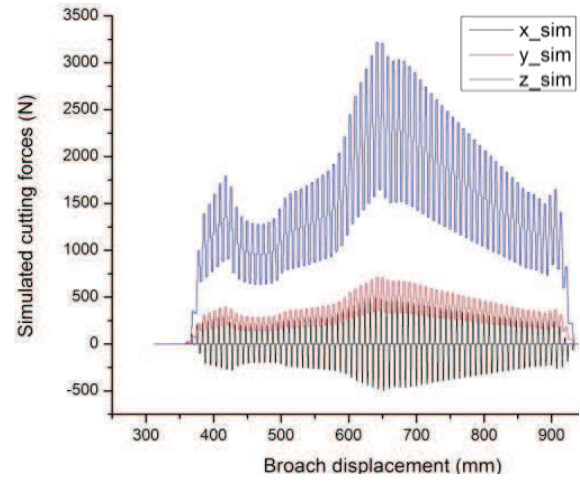

(a)

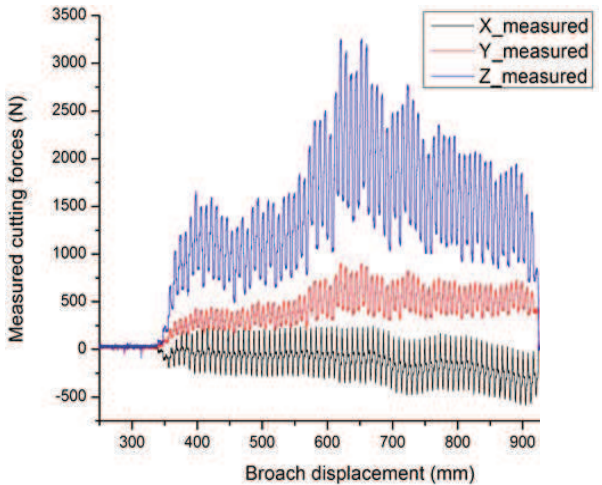

(b)

\section{Choice of the cutting model for industrial application}

This study presents two cutting models: one for orthogonal cutting, the other for oblique cutting. Difference between both models for the fir tree broach tested here is very low: less than 4\% (Figure 10) because of the very low inclination angle of this broach.

For similar case to this study (low $\lambda_{s}$ ), orthogonal cutting model is sufficient enough to simulate the cutting forces. This model provides two main advantages: it only requires measurement of $F_{t}$ and $F_{r}$ and modelisation is very easy (no mechanical knowledge of cutting is needed), so this model can be used very easily in the industrial field.

In the case of an important inclination angle, the oblique cutting model is compulsory. This model allows, by means of orthogonal cutting test, the modelisation of oblique cutting process, but requires measurement of the chip thickness in addition to $F_{t}$ and $F_{r}$. This model also implies a better knowledge of metal cutting to model and understand shear stress, shear angle and friction coefficients. This model seems to be less usable in the field of industry but it is very interesting in the field of research.

The border between the need of orthogonal cutting model and oblique cutting model has not been verified by experimental investigations because of the cost of a new broach to verify this point only. Both models are mechanistic models. They are sufficient to modelise cutting forces but they are not sufficient to understand the cutting process. Analytical models, as already done by Germain (2011) for turning, can be a great help to 
go further. But, because of even more difficult realisation of analytical models, they are not directly suitable for the industrial field.

With both cutting force models of the simulation the industrial can simulate cutting force for new tools design, develop process monitoring strategies based on a better understanding of the cutting process, and also modify the roughing or the finishing shapes to evaluate the influence of miss aligned tools on the cutting forces.

\section{Conclusions}

A methodology to simulate cutting forces in fir-tree broaching is proposed in this article. By means of orthogonal cutting tests, two cutting force models are provided: one for orthogonal cutting and the other for oblique cutting. By computation of cutting parameter $\left(f, \gamma_{n}, \lambda_{s} \ldots\right)$ of each discretized section of each tooth, cutting models are implemented in a MATLAB ${ }^{\circledR}$ code to simulate the cutting forces. Elementary forces are associated to each discretized section according to the cutting parameters also computed in the MATLAB® code. Cutting forces variations are associated to the cutting section variation and explain force peaks. The orthogonal cutting model is accurate enough to simulate the cutting forces with a low inclination angle. To go further, analytical models will be a great help to understand the cutting process in broaching.

This simulation allows to collect a lot of important data and measured cutting forces of fir tree broach become understandable. Simulation was compared with measured cutting forces and some lack of fit was explained by the miss of alignment of roughing and finishing tools. Future work will be concentrated to develop an interval of tolerance of cutting forces, and simulations of miss-aligned tools. This simulated cutting forces with tolerance will be used for the development of process monitoring strategies and develop new broach designs. For example, to prevent tool breakage, the maximum force loading on each tooth could be determined; the rake angle variation along the cutting edges could be evaluated; finally, the period of new broach development could be decreased by simulation of cutting forces and then limitation of cutting trials.

\section{Acknowledgements}

This study has been done by the financial and technical support of Turbomeca. All the experimental tests have been performed in Turbomeca workshop.

\section{References}

Albrecht, P. (1960) 'New developments in the theory of the metal-cutting process, part 1', Journal of Engineering for Industry, No. 8, pp.348-358.

Amarego, E.J.A. and Withfield, R.C. (1985) 'Computer based modeling of popular machining operations for force and power prediction', Annals of the CIRP, Vol. 34, No. 1, pp.357-362.

Axinte, D. and Gindy, N. (2003) 'Tool condition monitoring in broaching', Wear, Vol. 3, No. 254, pp.370-382.

Bellais, C. (1997) 'Brochage', Technique de l'ingénieur, Vol. 1, No. 7087. p.19. 
Budak, E., Altintas, Y. and Amarego, E.J.A. (1996) 'Prediction of milling force coefficients from orthogonal cutting data', Journal of Manufacturing Sciences an Enginerring, Vol. 118, No. 2 , pp.219-224.

Germain, D. (2011) Development of a Cutting Force Model Which Integrates Tool Flank Contact: Application on Cupper Turning in Super-Finition, Published $\mathrm{PhD}$ thesis, Ecole national supérieure d'art et métiers, Cluny, France [online] http://www.pastel.archives-ouvertes.fr (accessed 13 August 2013).

Kokturk, U. and Budak, E. (2004) 'Optimisation of broaching tool design', Paper presented at the CIRP Intelligent Computation in Manufacturing Enginerring, Sorrento, June.

Mandrile, S., Dessein, G., Denape, J., Paris, J-Y., Cazenave-Larroche, G. and Vernault, C. (2012) 'Identification and modelization of cutting phenomena in broaching to understand tool wear', Paper presented at the $M U G V-2012$, Saint Etienne, France.

Ozturk, O. and Budak, E. (2003) 'Modeling of broaching process for improved tool design', Paper presented at the International Mechanical Enginnering Congress and Exposition, Washington, DC.

Stephenson, D.A. and Bandyopadhyay, P. (1997) 'Process - independent force characterization for metal cutting simulation', Journal of Engineering Materials and Technology, Vol. 1, No. 119, pp.86-94.

Sutherland, J.W., Salisbury, E.J. and Hoge, F.W. (1997) 'A model for the cutting force system in the gear broaching process', International Journal of Machine Tools and Manufacture, Vol. 37, No. 10, pp.1409-1421.

Terry, W.R., Karni, R. and Huang, Y. (1992) 'Concurent tool and production system design for a surface broach cutting tool: a knowledge-based systems approach', International Journal of Production Research, Vol. 30, No. 2, pp.219-240.

Zhang, Y.L. and Chen, W.Y. (2012) 'Finite element modeling of broaching process of Inconel 718’, Material Science Forum, Vol. 697, No. 69, pp.39-43.

\section{Nomenclature}

\begin{tabular}{ll}
\hline$b$ & Width of cut [mm]. \\
$f$ & Feed per tooth [mm]. \\
$h$ & Chip thickness [mm]. \\
$P$ & Pitch of the broach [mm]. \\
$e p$ & Thickness of the machined workpiece [mm]. \\
$F_{x}, F_{y}, F_{z}$ & Cutting forces in the $\vec{x}, \vec{y}, \vec{z}$ axes system [N]. \\
$F_{b}, F_{r}, F_{a}$ & Tangential, radial and axial cutting forces [N]. \\
$F t c, F_{r c}, F_{a c}$ & Tangential, radial and axial forces due to the rake face [N]. \\
$F t e, F_{r e}, F_{a e}$ & Tangential, radial and axial forces due to the cutting edge \\
$K_{b}, K_{r}$ & [N]. \\
$K_{t c}, k_{r c}, K_{a c}$ & Normalised cutting forces in orthogonal cutting [MPa]. \\
$K_{t e}, k_{r e}, K_{a e}$ & Tangential, radial and axial cutting coefficients due to the \\
$\gamma_{n}, \gamma_{o}$ & rake face [MPa]. \\
$\lambda_{s}$ & Tangential, radial and axial cutting coefficient due to the \\
\hline
\end{tabular}




\begin{tabular}{|c|c|}
\hline$\phi_{n}$ & Normal shear angle [degrees]. \\
\hline$\beta_{n}$ & Friction angle [degrees]. \\
\hline$\tau_{s}$ & Shear stress in the shear plane [MPa]. \\
\hline$H$ & High of the fir tree $[\mathrm{mm}]$. \\
\hline$d$ & Discretization of the fir tree along the $\vec{y}$ axis $[\mathrm{mm}]$. \\
\hline$m$ & Number of teeth of the broach [mm]. \\
\hline$Y_{\text {slot discretization }_{n^{* 1}}}$ & $\begin{array}{l}y \text { coordinates of the slot. Matrix with } n \text { lines and } 1 \text { colon } \\
\text { [mm]. }\end{array}$ \\
\hline$X_{\text {fir tree slot } n^{*} 1}$ & $x$ coordinate of the fir tree. Matrix $n$ lines and 1 colon $[\mathrm{mm}]$. \\
\hline$X_{\text {roughing }_{n^{*} 1}}$ & $\begin{array}{l}x \text { coordinate of the roughing shape. Matrix } n \text { lines and } 1 \\
\text { colon }[\mathrm{mm}] .\end{array}$ \\
\hline$X_{\text {broach teeth } h_{n^{*} m}}$ & $\begin{array}{l}x \text { coordinate of each tooth of the broach. Matrix } n \text { lines and } \\
\mathrm{m} \text { colons }[\mathrm{mm}] .\end{array}$ \\
\hline$f_{\text {broach }}{ }_{n_{n^{*} m}}$ & $\begin{array}{l}\text { Feed of each discretized section of each tooth. Matrix } n \\
\text { lines and } m \text { colons [mm]. }\end{array}$ \\
\hline disp & $\begin{array}{l}\text { Discretization along the } \vec{z} \text { axis of the broach displacement } \\
\text { [mm]. }\end{array}$ \\
\hline le & Length of the broach [mm]. \\
\hline$\alpha_{\text {workpiece }}$ & Inclination angle of the workpiece [degrees]. \\
\hline$G F T_{x_{r^{*} m_{m}}}, G F T_{y_{r^{*} m}}, G F T_{z_{r^{*} m}}$ & $\begin{array}{l}\text { Global force of each tooth in the } \vec{x}, \vec{y}, \vec{z} \text { axes system. } \\
\text { Matrixes } r \text { lines and } m \text { colons }[\mathrm{N}] .\end{array}$ \\
\hline$G F_{x_{r+1}}, G F_{y_{r^{r} \mid}}, G F_{z_{r^{*} \mid}}$ & $\begin{array}{l}\text { Global forces in the } \vec{x}, \vec{y}, \vec{z} \text { axes system. Matrixes } r \text { lines } \\
\text { and } 1 \text { colon }[\mathrm{N}] \text {. }\end{array}$ \\
\hline
\end{tabular}

